\title{
Construction company administration of intangible resources in the face of uncertainty
}

\author{
S.A. Kurgansky \\ ${ }^{1}$ Irkutsk National Research Technical University, 83 Lermontov str., Irkutsk, 664074, \\ Russia
}

\begin{abstract}
Management of intangible resources is an important component of a construction company's business processes. The rapid development of information technology forces construction companies to change their usual activities and rebuild business processes in accordance with the challenges of the real market. It is digital technologies that are the object of the company's intangible assets that can be used much more effectively to improve the current processes and information flows in the construction company. The advantages of the construction company's intangible assets, such as Smart spaces, are that they provide increased efficiency and lower production costs, achieved through rational actions, the use of faster and more secure communication methods that guarantee the necessary flow of information. They also improve efficiency through rational and timely actions, with an emphasis on creating value and using new technologies. The economic effect of using information technologies, namely the introduction of Smart spaces, can be either direct, material in the form of achieved cost reduction and increased productivity of operations, or non-material, in the form of implemented patents and licenses, and improving the company's image, as well as the potential of information technologies that can be used to make more effective decisions of a strategic nature.
\end{abstract}

At the present stage of business development in a knowledge-based economy, the share of intangible resources in the market capitalization of enterprises, and, consequently, their role in the production of goods and services, is steadily growing. In the knowledge economy along with financial resources are an important source of competitiveness of the organization are such "intangible" resources, such as: the ability of staff to successfully perform tasks, clever use of information environment of the enterprise, as well as the presence of organizational culture. The transition of the Russian economy to market-based forms of management required construction companies to radically revise the basic provisions of the concept of managing intangible resources. First of all, this is due to the fact that elements of unpredictability of changes in the economic environment of enterprises that occur at a rapid pace both at the microeconomic and macro-economic level of the developing market have appeared and are becoming more and more pronounced. In this regard, there is an objective need to develop effective methods of managing intangible resources of a construction company in the conditions of instability and uncertainty caused by poorly predictable changes in the modern market.

Real-time management of intangible resources is a complex scientific and technical problem, the practical solution of which will allow companies to manage the efficiency of business processes by quickly responding to events and eliminating the shortage or downtime of resources. Various software packages are used by construction companies to solve problems of managing intangible resources. However, with the increasing complexity and dimension of these tasks, as well as due to the growing 
uncertainty in the forecasts of changes in demand and supply in the market, the use of classical methods and tools in practice meets significant difficulties, largely due to the situational nature of decisions on resource management and the requirement to take into account the individual characteristics of construction companies.

In these situations, it is necessary to develop standard models and methods for solving various problems of situational management of intangible resources of a construction company, for which no unified approaches have been created so far, as well as to build a software platform and technology that could be applied to create a wide range of intelligent resource management systems in real time and would reduce the labor intensity, time and cost of construction projects.

A construction company is a complex socio-economic object that closely interacts with a dynamic market environment during its operation. The modern Russian market, which determines the nature of the functioning and development of a construction company, can be characterized by instability, high risks associated with a priori unpredictable changes in the market environment, for example, due to unfair competition in the construction industry. Various factors of the market environment, changing, significantly affect the efficiency of the construction company, affecting its internal economic environment. Therefore, to effectively manage the production and economic activities of a construction company, it is necessary to know the causes of risk factors, the nature of their manifestation and the nature of their impact on production processes. If there are limited intangible resources, it leads to a constant shortage of information about the behavior of the market environment and reduces the effectiveness of the management object. The second reason why the management system is forced to function in conditions of uncertainty is the dynamism and a priori unpredictability of changes occurring in the market.

Implementation of methods for managing the construction company's intangible resources, based on extrapolation of the construction company's behavior in conditions of uncertainty, represents the formation of an effective mechanism for "proactive regulation" of the company's business processes. In this case, we are talking about planning and conducting proactive management measures in accordance with the forecast estimates of changes in the situations of the external and internal environment of the construction company, obtained through the use of the company's intangible resources.

Intangible resources are one of the most important components of the activities of construction companies in an unstable economic environment. The definition of a strategy for the use of intangible resources in a construction company depends fundamentally on the specific situation in which it is located and the planned prospects for its development. However, when designing a strategy for the use of intangible resources, it is necessary to proceed from the fact that there are common approaches to their formulation and some common frameworks that fit different strategies.

A significant influence on the choice of methodological support for the management of intangible resources of a construction company has a factor such as the dynamics of the surrounding economic environment. Depending on the speed of processes occurring in the external environment and the nature of their changes, environments can be slow and fast changing situations. For environments with a slow change of situations, the strategy of using the company's intangible resources in the external environment can be quite stable and adjusted if necessary in the event of changes in the internal environment of its functioning. With a rapid change in the external environment, the construction company faces uncertainty in the conditions of its behavior, on the basis of this, the management of intangible resources should be adaptive, that is, change in accordance with changes in the economic environment. At the same time, the following elements should be provided and implemented to form an adaptive strategy for managing the construction company's intangible resources:

- formation of NMR characteristics required for the implementation of strategic goals and key business processes of the enterprise

- $\quad$ assessment of the current state of the NMR as the degree of compliance of the actual characteristics with the required

- $\quad$ identification of possible solutions for managing NMR 
- $\quad$ quantitative assessment of the effectiveness of control actions and implementation of the most effective ones

- $\quad$ verification of the effectiveness of decisions taken to manage NMR

In order to assess the current state of the enterprise's NMR, it is necessary to determine the strategic readiness of intangible resources. Strategic readiness indicates the degree of compliance of the actual state of intangible resources with the target characteristics and ensure the following:

- when allocating available or incoming funds, the construction firm should leave bumper stocks in case of unforeseen situations

- the main indicators that determine the technical and economic condition of a construction company should be set by interval estimates, whose boundary values are determined by the minimum allowed and maximum possible values.

- the organization of the structure of the construction company should be based on a matrix type, allowing the formation and dissolution, as necessary, of problem-oriented functional divisions

- availability of a powerful environmental monitoring system that regularly collects information about changes in the environment and determines trends in its development on this basis

- integration of feedbacks into various contours of the construction company's strategic management

- $\quad$ ensuring the possibility of changing the tactics of behavior in the market in the event of unforeseen short-term spontaneous changes at the expense of existing reserves.

All the above measures for managing intangible resources should be effectively organized using Internet technologies. Currently, the technological development of construction companies is accompanied by a sharp increase in the demand for information and the expansion of the use of information technologies. This is facilitated by the rapid development of information systems and new areas of information production, such as "Big Data", "Internet of things", "cloud technologies", "digital fields" (DMS) and other advanced technologies. Together, they can create a serious potential for improving the performance of construction companies.

Construction organizations differ significantly in the degree of integration of Internet technologies in their production and management practices. Some organizations have revised their approaches to the implementation of only certain management functions, such as marketing and personnel management, based on the active use of Internet technologies, while other construction companies have redesigned the main and supporting business processes based on Internet platforms.

Experts predict that the greatest success is possible when using real-time management methods and technologies, scenario modeling tools, and decision support in conditions of risk and uncertainty. In this context, Smart technologies are becoming a powerful tool for improving efficiency, since they allow you to design a single space for all holders of business processes of an investment and construction project, which allows you to provide remote control in the "online" mode, and also improves the quality of management decisions, which significantly affects the reduction of production costs.

Based on the analysis of the Smart technologies market, the key methods and areas of application of information technologies in the processes of evaluating the effectiveness of business processes of a construction company were identified (table 1).

Table 1. Methods and areas of application of information technologies in the processes of evaluating the effectiveness of business processes of a construction company

\begin{tabular}{|c|c|c|c|}
\hline $\begin{array}{l}\text { Investment-oriented } \\
\text { Smart technologies }\end{array}$ & $\begin{array}{l}\text { Cost-oriented } \\
\text { Smart } \\
\text { technologies }\end{array}$ & hnologies refle & $\begin{array}{l}\text { nologies } \\
\text { fication }\end{array}$ \\
\hline $\begin{array}{l}\text { 1. Costs-benefits } \\
\text { 2. Uncertainty of the } \\
\text { future } \\
\text { 3. Diagnostics of }\end{array}$ & 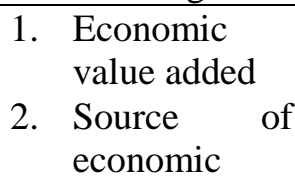 & $\begin{array}{ll}\text { 1. } & \text { Method balanced } \\
\text { scorecard } \\
\text { 2. } \\
\text { 3. } \\
\text { Information economy }\end{array}$ & $\begin{array}{l}\text { 1. Real Options } \\
\text { Valuations } \\
\text { 2. App } \\
\text { 3. Applied }\end{array}$ \\
\hline
\end{tabular}




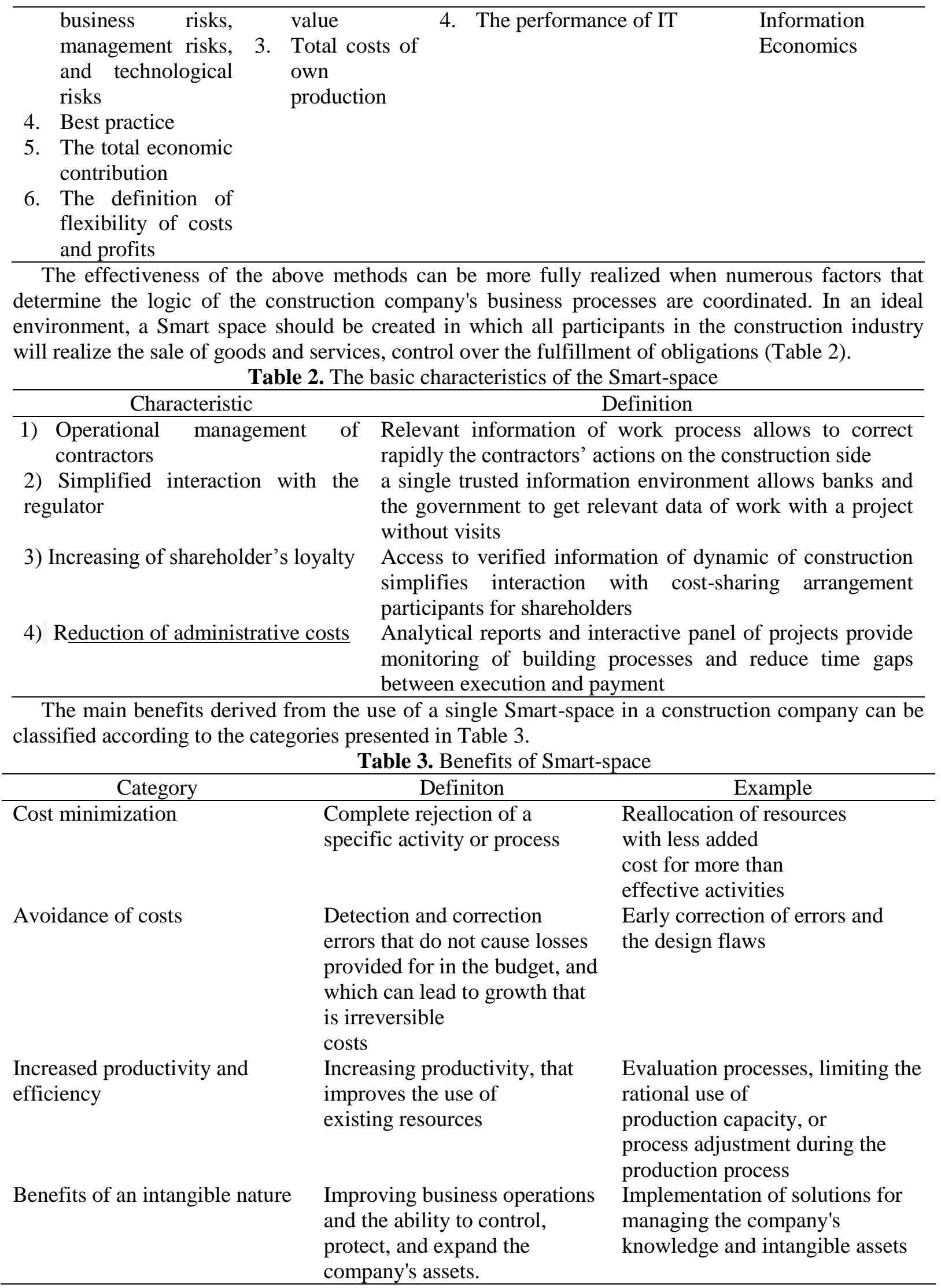


The results shown in the table show that the greatest benefits from the use of Smart technologies are reflected in terms of economy and technology particularly increased productivity, improved process efficiency and increased profitability. Increasing productivity by using of Smart technologies will allow you to standardize processes and systems used throughout the enterprise, which optimizes the work of both management personnel and production. In turn, saving time by automating processes such as data collection, processing, and reproduction optimizes decision-making processes by obtaining more reliable information in a timely manner.

Based on the conducted research and analysis of the literature it can be concluded that the introduction of Smart technologies in the business processes of construction companies will reduce transaction costs by improving efficiency, increase revenues, by increasing the pace of construction, reduce overhead costs and provide for asset management and business processes of investment and construction project in real-time, based on the use of the latest information allowing them to make the most accurate, optimal and cost-effective solutions.

\section{References}

[1] Matveeva M 2018 Synchronization of the activity of participants during the implementation of housing construction projects Proceedings of Universities. Investment. Construction. Real estate 8 pp 31-41 DOI: 10.21285/2227-2917-2018-2-31-41.

[2] Matveeva M V, Doroshenko T G and Sukhanova I A 2019 On the issue of cost and timing of contract tenders for industrial and civil construction Investments. Construction. Real Estate: New Technologies and Targeted Development Priorities IOP Conference Series: Materials Science and Engineering 667012063

[3] Kalyuzhnova N, Violin S and Matveeva M 2019 Smart Specialization of Russian Regions: Prospects and Limitations Investments. Construction. Real Estate: New Technologies and Targeted Development Priorities IOP Conference Series: Materials Science and Engineering $\mathbf{6 6 7 0} 012036$

[4] Skolubovich A Yu and Matveeva M V 2019 Development of a methodology for assessing the readiness of enterprises for public-private partnership in the field of public water supply Proceedings of Universities. Investment. Construction. Real estate 9 pp 274-283 DOI: 10.21285/2227-2917-2019-2-274-283

[5] Chupin V R and Maizel D I 2020 Aggregation and decomposition in routing oil and gas pipeline systems Proceedings of Universities. Investment. Construction. Real estate 10(1) pp 108-115https://doi.org/10.21285/2227-2917-2020-1-108-115

[6] Biglova A A 2018 State of the public procurement system in Russia Science, education, innovation: approbation of research results Materials of the International (correspondence) scientific and practical conference pp 153-156

[7] Gaskova Yu.I. "Integrative approach to the formation of a mechanism for the coordinated development of industry and infrastructure in the region" // Proceedings of the II International scientific and practical conference "Economics and modern management: theory, methodology and practice". - Penza: 2018. - p.358-362.

[8] Komarov A K, Ivanov I A and Lundenbazar B 2019 Theory and practice of the use of gabions for forming protective structures Proceedings of Universities. Investment. Construction. Real estate 9(1) pp 78-89 DOI: 10.21285/2227-2917-2019-1-78-89

[9] Peshkov V V and Gamayunova E V 2018 Specific features of investment support for the repair and reconstruction of buildings and facilities Proceedings of Universities. Investment. Construction. Real estate 8 pp 56-72 DOI: 10.21285/2227-2917-2018-2-56-72

[10] Yaskova N Yu and Sarchenko V I 2018Development of strategic approaches to the creation of aqua-territorial industrial complexes in the Arctic zone Proceedings of Universities. Investment. Construction. Real estate 8 pp. 84-93 DOI: 10.21285/2227-2917-2018-2-84-93

[11] Kudryavtseva V A, Zaslavsky A M and Larina O P 2018 Multicriterial comparison at the 
inclusion of investment projects of manufacture of building materials into the state program of the region (at the example of Irkutsk region) Proceedings of Universities. Investment. Construction. Real estate 8 pp 60-72 DOI: 10.21285/2227-2917-2018-1-60-72

[12] Gertsekovich D, Gorbachevskaya L, Grigorova L and Peshkov V 2019 Return on investment in REIT real estate funds Investments. Construction. Real Estate: New Technologies and Targeted Development Priorities IOP Conference Series: Materials Science and Engineering 667012063

[13] Matveeva M, Kalyuzhnova N, Skripka S 2019 Intellectual specialization of Russian regions: prospects and limitations IOP Conf. Series: materials Science and engineering 667

[14] Sayfutdinova R V 2016 Modern Fundamental and Applied Researchers 1(20) pp 167-173

[15] Vovseenko E A 2018 Financial Instruments and Hedging: New Rules of IFRS European Proceedings of Social and Behavioural Sciences L DOI: https://dx.doi.org /10.15405/epsbs.2018.12.167

[16] Khokhlova G., Kretova N., Burov V. 2019 The problems of investment activity of entrepreneurship and methodological aspects of credit risks assessment, ICRE IOP Conference series: materials science and engineering $\mathbf{6 6 7}$ DOI:10.1088/1757$899 X / 667 / 1 / 012038$ 